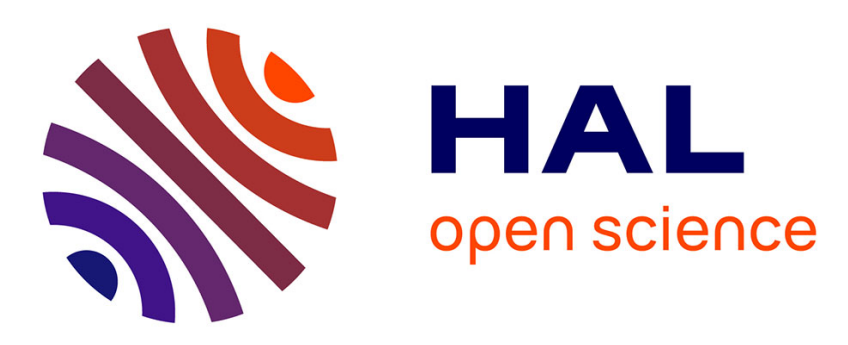

\title{
Effect of interlamellar spacing on the elastoplastic behavior of C70 pearlitic steel: Experimental results and self-consistent modeling
}

\author{
Houda Yahyaoui, H Sidhom, Chedly Braham, A. Baczmanski
}

\section{- To cite this version:}

Houda Yahyaoui, H Sidhom, Chedly Braham, A. Baczmanski. Effect of interlamellar spacing on the elastoplastic behavior of C70 pearlitic steel: Experimental results and self-consistent modeling. Materials \& Design, 2014, 55, pp.888-897. 10.1016/j.matdes.2013.10.062 . hal-00980349

\author{
HAL Id: hal-00980349 \\ https://hal.science/hal-00980349
}

Submitted on 4 Jul 2014

HAL is a multi-disciplinary open access archive for the deposit and dissemination of scientific research documents, whether they are published or not. The documents may come from teaching and research institutions in France or abroad, or from public or private research centers.
L'archive ouverte pluridisciplinaire HAL, est destinée au dépôt et à la diffusion de documents scientifiques de niveau recherche, publiés ou non, émanant des établissements d'enseignement et de recherche français ou étrangers, des laboratoires publics ou privés. 


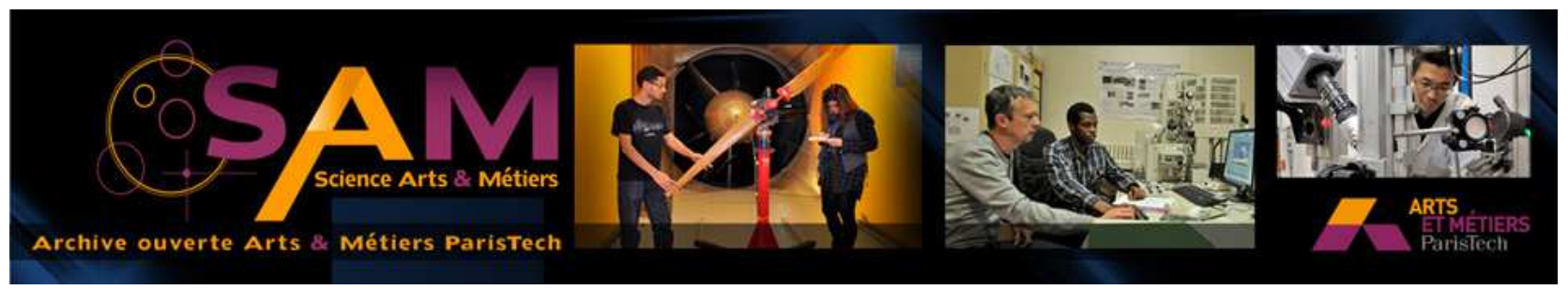

Science Arts \& Métiers (SAM)

is an open access repository that collects the work of Arts et Métiers ParisTech researchers and makes it freely available over the web where possible.

This is an author-deposited version published in: http://sam.ensam.eu Handle ID: .http://hdl.handle.net/10985/7977

\section{To cite this version :}

Houda YAHYAOUI, H SIDHOM, Chedly BRAHAM, A. BACZMANSKI - Effect of interlamellar spacing on the elastoplastic behavior of $C 70$ pearlitic steel: Experimental results and selfconsistent modeling - Materials and Design - Vol. 55, p.888-897 - 2014 


\title{
Effect of interlamellar spacing on the elastoplastic behavior of C70 pearlitic steel: Experimental results and self-consistent modeling
}

\author{
H. Yahyaoui ${ }^{\mathrm{a}, \mathrm{b}}$, H. Sidhom $^{\mathrm{a}, *}$, C. Braham ${ }^{\mathrm{b}}$, A. Baczmanski ${ }^{\mathrm{c}}$ \\ ${ }^{a}$ Mechanical, Materials and Processes Laboratory (LR99ES05), ESSTT, 5, Avenue Taha Hussein 1008, University of Tunis, Tunisia \\ ${ }^{\mathrm{b}}$ Laboratoire Procédés et Ingénierie en Mécanique et Matériaux (PIMM, CNRS UMR 8006), Arts et Métiers-ParisTech, 151 Bd de l'Hôpital, 75013 Paris, France \\ ${ }^{\mathrm{c}}$ AGH-University of Science and Technology, Faculty of Physics and Applied Computer Science, Al. Mickiewicza 30, 30-059 Kraków, Poland
}

Keywords:

Pearlitic steel

X-ray diffraction

Self-consistent model

Critical shear stress

Residual stress

\begin{abstract}
A B S T R A C T
The effect of pearlite microstructure characteristics on strength and deformation of C70 pearlitic steel was investigated. Tensile tests under X-ray diffraction coupled with self-consistent model have been used to identify the role of interlamellar spacing on the ferrite plasticity parameters and residual stress induced by plasticity. Tests have been carried out on two pearlitic microstructures with interlamellar spacing $\mathrm{Sp}=170$ and $230 \mathrm{~nm}$ respectively. Ferrite critical shear stresses $\left(\tau_{c}^{0}(\alpha)\right)$ are equal to $75-86 \mathrm{MPa}$ for interlamellar spacing $\mathrm{Sp}=230 \mathrm{~nm}$ and $105-120 \mathrm{MPa}$ for interlamellar spacing $\mathrm{Sp}=170 \mathrm{~nm}$. Moreover, the compressive residual stress measured in ferrite phase is higher in elasto-plastically deformed sample (total strain of $\left.E_{11}=1.2 \%\right)$ having larger interlamellar spacing $\left(\sigma_{\text {Fex }}^{R}=-161 \mathrm{MPa}\right.$ for $\mathrm{Sp}=230 \mathrm{~nm}$ and $\sigma_{\text {Fex }}^{R}=-77 \mathrm{MPa}$ for $\mathrm{Sp}=170 \mathrm{~nm}$ ).
\end{abstract}

\section{Introduction}

Pearlitic steels have important applications when high strength and wear resistance are required. They are usually used in manufacturing of railroad rails, engineering springs, wire and suspension cables [1-3]. Nevertheless, the behavior of these materials is very sensitive to the microstructure characteristics like pearlitic colonies, early austenitic grain size and cementite volume fraction and shape. The effect of microstructure has been discussed on the basis of load partitioning between ferrite and cementite phases assessed by "in situ» tensile tests under X-ray [4,5], synchrotron [4-7] and neutron diffraction [8-11]. It has been established that for the fully pearlitic structures, the load partitioning is mainly controlled by cementite shape and the interlamellar spacing:

\subsection{Globular pearlite}

In the case of JIS SK5 and SK3 carbon steels, Lei et al. [12] showed various stress partitioning under loading and after unloading as a function of volume fraction and particle size of spheroidal cementite. Moreover, the authors observed an elastic behavior of cementite and ferrite when the spheroidized carbon steels are elastically loaded. However, at higher loaded condition, the softer fer-

\footnotetext{
* Corresponding author. Tel.: +216 71496 066; fax: +216 71391166

E-mail addresses: Yahyaoui_houda08@yahoo.fr (H. Yahyaoui), habib.sidhom@gmail.com (H. Sidhom), chedly.braham@ensam.eu (C. Braham), Andrzej.Baczmanski @fis.agh.edu.pl (A. Baczmanski).
}

rite plastically deforms whereas the harder cementite remains elastic in a linear manner until fracture [13]. Young et al. [6] studied a load partitioning between ferrite and spheroïdal cementite during elastoplastic deformation of an ultrahigh-carbon steel and showed that, in the elastic range of deformation, no load transfer occurs between ferrite and cementite because both phases have nearly equivalent elastic properties. However, in the plastic range of deformation, after Lüders band propagation, load transfer takes place from the plastically deforming matrix (ferrite) to the elastic cementite particles. The load transfer between ferrite and cementite in the plastic deformation range of the steel has also been reported in other studies $[9,11,14]$.

\subsection{Lamellar pearlite}

In the case of $0.8 \% \mathrm{C}$ lamellar pearlitic steel Shinozaki et al. [15] showed that stress partitioning between ferrite and cementite is influenced by lamellar spacings. They reported that the phase stress is increased with decreasing the lamellar spacing and that the elastic strain in the ferrite matrix after the onset of plastic flow is increased with decreasing the lamellar spacing as well. Hyzak and Bernstein [16] showed that the strength of fully pearlitic steel is controlled primarily by the interlamellar spacing, while the toughness is strongly dependent on the prior-austenitic grain size. It has been reported by several investigators [17-19] that the strength of pearlitic steels follows a Hall-Petch type relationship with respect to the interlamellar spacing. 
The effect of interlamellar spacing on the strength of pearlite has been explained on the basis of a dislocation pile-up model and the mean free path of the mobility of dislocations [2,20,21]. Otherwise, Dollar et al. [18] showed that the work hardening of pearlite does not depend on the interlamellar spacing.

The quantitative evaluation of loading partitioning and phase behavior of pearlitic steels needs neutron [8-11] and synchrotron [4-6] diffraction methods which are restricted to a limited number of specialized laboratories. X-ray "in situ» tensile tests encounters difficulties associated with low intensity diffraction peak of cemetite phase. They only provide information about ferrite behavior $[4,5]$. That is why, several studies have used self-consistent models $[4,5,9,14,22]$ to identify the behavior of pearlitic steels at macroscopic and microscopic scales under monotonic $[4,9,22]$ and cyclic [23] loading. The self-consistent model has been used by Inal et al. [4] in the case of pearlitic steel ( $88 \%$ ferrite and $12 \%$ cementite) to identify the elastoplastic parameters (critical shear stress and hardening parameter) of ferrite. Schmitt et al. [22] developed a model based on Mori-Tanaka scheme to describe the elastoplastic behavior of hypo and hyper-eutectoid steels. The transition of the single crystal phase to the polycrystal level is achieved by the selfconsistent model. The elastoplastic parameters of ferrite and the residual stress in each phase were determined by this model.

Nevertheless, a few works have been published on the effect of interlamellar spacings on the critical shear stress $\tau_{c}$ and hardening parameter $\mathrm{H}$ of ferritic phase that constitutes the pearlitic structure of carbon steels. Indeed, results of Shinozaki et al. [15] are only limited to the experimental assessment of stress partitioning between ferrite and cementite under tensile loading of various pearlitic structures without any attempt to identify the effect of interlamellar spacing on the elastoplastic parameters of ferrite.

For these reasons, the present study was undertaken to clarify the microstructure-tensile properties relationship of C70 fully pearlitic steel with similar prior austenitic grain size and pearlite colonies size but with different interlamellar spacings. X-ray diffraction coupled with self-consistent model is used to identify the role of the interlamellar spacing on the pearlite strength, the ferrite plasticity parameters and the residual stress induced by plasticity.

\section{Material and heat treatments}

\subsection{Material}

The pearlitic steel EN C70 (SAE 1070), studied in this work, was provided by ASCOMETAL France company in the form of cylindrical bars of $80 \mathrm{~mm}$ in diameter obtained by hot rolling. The chemical composition of this steel is given in Table 1 .

\subsection{Heat treatments and microstructure characteristics}

Two annealing treatments have been selected to provide two different pearlitic microstructure configurations (Fig. 1). Specimens were polished successively using fine silicon carbide papers from 100 to 4000 grit, fine polishing with $3 \mu \mathrm{m}$ water-based diamond suspension and etched in 3\% Nital solution. The random intercept method [24] was used to determine the prior austenite grain size whereas scanning electron microscope (SEM) examinations were used to provide colonies size. A circular line method

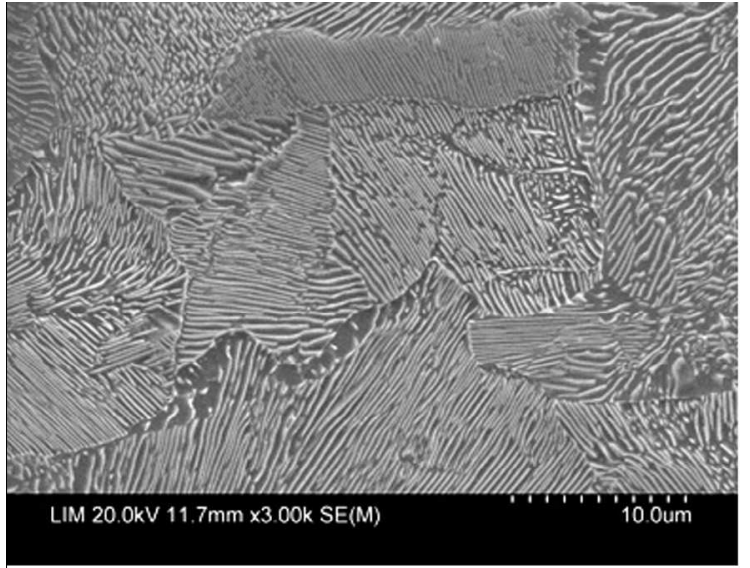

(a)

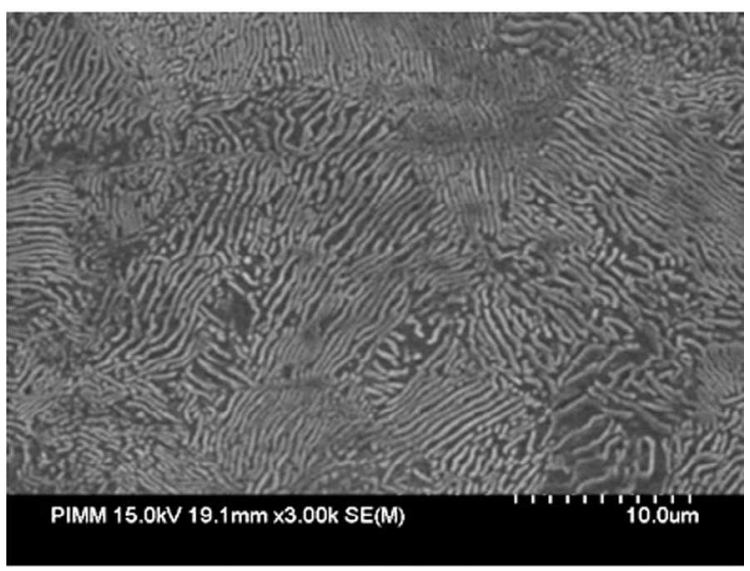

(b)

Fig. 1. Microstructures of C70 pearlitic steel: (a) austenizing at $1073 \mathrm{~K}$ for $0.5 \mathrm{~h}$ followed by cooling under calm air (HT1); (b) austenizing at $1323 \mathrm{~K}$ for $0.11 \mathrm{~h}$ followed by cooling under blowing air (HT2).

(CLM), which is valid for global randomly distributed lamellae [25] was used to measure the average interlamellar spacing (Fig. 2):

$S_{p}=\frac{0.5 L}{N}$

where $L$ is length of the circle and $N$ is the number of intersections between the circular line and the lamellae. The analysis of at least 25 pictures resulted in an average interlamellar spacing. Table 2 summarizes the annealing treatment conditions and the resulting microstructures characteristics.

\section{Experimental setup}

\subsection{Conventional tensile test}

The mechanical properties of the $\mathrm{C} 70$ pearlitic steel, including the yield and tensile strengths as well as the percent elongation, were determined for the two microstructures by tensile tests.

Table 1

Chemical composition of C70 pearlitic steel (wt\%).

\begin{tabular}{|c|c|c|c|c|c|c|c|c|c|c|}
\hline$C$ & $\mathrm{Si}$ & $\mathrm{Mn}$ & $\mathrm{S}$ & $\mathrm{P}$ & $\mathrm{Ni}$ & $\mathrm{Cr}$ & Mo & $\mathrm{Cu}$ & $\mathrm{Al}$ & $\mathrm{Fe}$ \\
\hline 0.68 & 0.192 & 0.846 & 0.010 & 0.010 & 0.114 & 0.160 & 0.027 & 0.205 & 0.042 & Balance \\
\hline
\end{tabular}




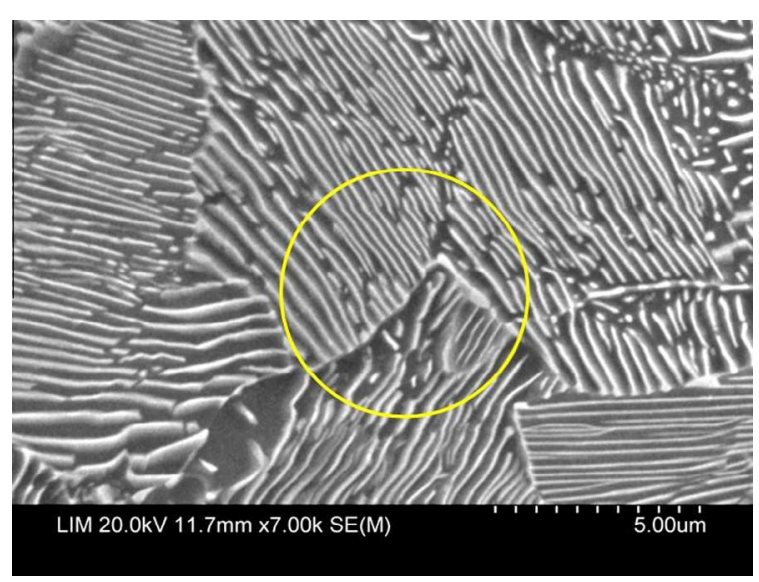

Fig. 2. Circular line method used for interlamellar spacing measuring.

Tensile specimens were machined by wire EDM (Electrical Discharge Machining) from the same circumference of a cylindrical bar. The tests were performed on an INSTRON 5881 mechanical test machine.

\section{2. «In situ» X-ray tensile test}

"In situ» tensile tests were performed on electropoliched specimens (Fig. 3). The macroscopic force corresponding to the imposed displacement is measured by an annular force sensor mounted on the "in situ» tensile test device (Fig. 3). The total strain is measured using a strain gage mounted on the specimen surface. The ferrite stress values are determined by X-ray measurement for each increment of displacement on the electropolished surface. The $\sin ^{2} \psi \mathrm{X}$ ray diffraction method was used to determine the stresses in the ferritic phase. This method is based on the measurement of peak positions for a given $h \mathrm{kl}$ reflection and for various directions of the scattering vector with respect to the sample. A Set-X type diffractometer was used to measure interplanar spacings for the extended range of $\sin ^{2} \psi$ and for negative and positive $\psi$ angles (Fig. 3). Measurements were determined using the operating conditions given in Table 3 and in accordance with NF EN 153052009 standard [26].

It is important to notice that the stress in cementite phase was not measured because the diffraction peak intensities from this phase ( $10 \%$ of total pearlitic volume) are very low.

\section{Results}

\subsection{Experimental results}

4.1.1. Effect of interlamellar spacing on the pearlitic steel behavior 4.1.1.1. Strength. Tensile characteristics of the different microstructures are reported in Table 2. Both the yield and ultimate tensile strengths of the $\mathrm{C} 70$ pearlitic steel were observed to increase with decreasing the interlamellar spacing. The dependence of mechanical properties on the pearlite interlamellar spacing (Sp) is usually described by Hall-Petch equation (Eq. (2)).

$\sigma_{j}=\sigma_{0}+k \cdot S_{p}^{-m}$

where $\sigma_{j}$ can represent the yield strength or the ultimate tensile strength, $\sigma_{0}$ is the friction stress, and $k$ is a material constant.

The exponent $\mathrm{m}$ is classically equal to $(-2)$ for hypo and hypereutectoid steels $[2,27]$ and reconsidered to be equal to $(-1)$ in the modified Hall-Petch relation in order to give a physical validation of friction stress $\sigma_{0}$ in the case of eutectoid steels $[17,18]$. Indeed, the representation of experimental results using classical Hall Petch relation $\left(\mathrm{Sp}^{-2}\right)$ leads to a negative intercept $\sigma_{0}$, which has no apparent physical meaning. However, using a modified Hall-Petch relation $\left(\mathrm{Sp}^{-1}\right)$, the parameters $\sigma_{0}$ and $k$ for $\mathrm{C} 70$ pearlitic steel has been identified and compared to literature results in Table 4.

4.1.1.2. Work hardening. The results of tensile tests for the studied pearlitic structures were fitted by the Ludwik equation:

$\sigma_{f}=\sigma_{y}+k^{\prime} \cdot \varepsilon_{p}^{n}$

where $\sigma_{y}$ is the yield strength, $\varepsilon_{p}$ is the true plastic strain, $k^{\prime}$ is a constant and $n$ is a measure of work hardening rate.

The values of $k^{\prime}$ and $n$ for different microstructures, reported in Table 5, show a similar values of work hardening rate for both annealed microstructures. This means that cold work hardening does not depend on interlamellar spacing in the range of lamellar spacings explored in the present paper.

\subsubsection{Effect of interlamellar spacing on the ferrite behavior}

4.1.2.1. Under loading. The superimposition of macroscopic and microscopic (ferrite) stress-imposed strain curves reveals the effect of pearlitic microstructure characteristics, resulting from the two annealing treatments of C70 steel, on the tensile behavior of both ferritic softened phase and overall pearlitic steel (Fig. 4).

The beginning of plastic flow in ferritic phase is around $\Sigma_{11}=400 \mathrm{MPa}$ macroscopic applied stress for lower interlamellar spacing (HT2 treatment) and only $\Sigma_{11}=300$ MPa macroscopic applied stress for higher interlamellar spacing (HT1 treatment). This difference is mainly attributed to the pearlite microstructure (Sp values) since the initial residual stresses level is the same as reported in Table 7. Analyzing the stress evolution in ferritic phase it was found, that the ferritic intrinsic yield stress for HT2 microstructure is around $\sigma_{11}=280 \mathrm{MPa}$, which is higher than the ferritic yield stress $\sigma_{11}=210 \mathrm{MPa}$ determined for HT1 microstructure.

4.1.2.2. After unloading. The difference between the two pearlite phases (ferrite and cementite) behavior under tensile loading is considered to be responsible for the residual stress induced by plasticity. Indeed, X-ray diffraction measurements; performed after tensile loading (stress ratio $\frac{\Sigma_{11}}{R_{e}} \geqslant 1.1$ ) followed by total unloading showed a compressive residual stress generated in ferrite. The values of those stresses increases with increasing the total imposed strain (Fig. 5). However, the plastic induced compressive residual stresses are higher for the larger interlamellar spacing at the same imposed total strain (Fig. 6). This means that

Table 2

Heat treatments, metallurgical characteristics and mechanical properties of the two microstructures.

\begin{tabular}{|c|c|c|c|c|c|c|c|}
\hline Annealing treatment & $\begin{array}{l}\text { Colonies } \\
\text { size }(\mu \mathrm{m})\end{array}$ & $\begin{array}{l}\text { Grains size } \\
(\mu \mathrm{m})\end{array}$ & $\begin{array}{l}\text { Interlamellar } \\
\text { spacing Sp (nm) }\end{array}$ & $\begin{array}{l}\text { Yield stress } \\
(\mathrm{MPa})\end{array}$ & $\begin{array}{l}\text { Ultimate tensile } \\
\text { strength (MPa) }\end{array}$ & $\begin{array}{l}\text { Elongation } \\
(\%)\end{array}$ & $\begin{array}{l}\text { Hardness } \\
\mathrm{HV}_{50}\end{array}$ \\
\hline $\begin{array}{l}\text { HT1: Austenizing at } 1073 \mathrm{~K} \text { for } 0.5 \mathrm{~h} \text { followed by } \\
\text { cooling under calm air }\end{array}$ & 7.4 & 19 & 230 & 396 & 875 & 17 & $220 \pm 10$ \\
\hline $\begin{array}{l}\text { HT2: Austenizing at } 1323 \mathrm{~K} \text { for } 0.11 \mathrm{~h} \text { followed by } \\
\text { cooling under blowing air }\end{array}$ & 7.9 & 26 & 170 & 498 & 997 & 15 & $270 \pm 15$ \\
\hline
\end{tabular}




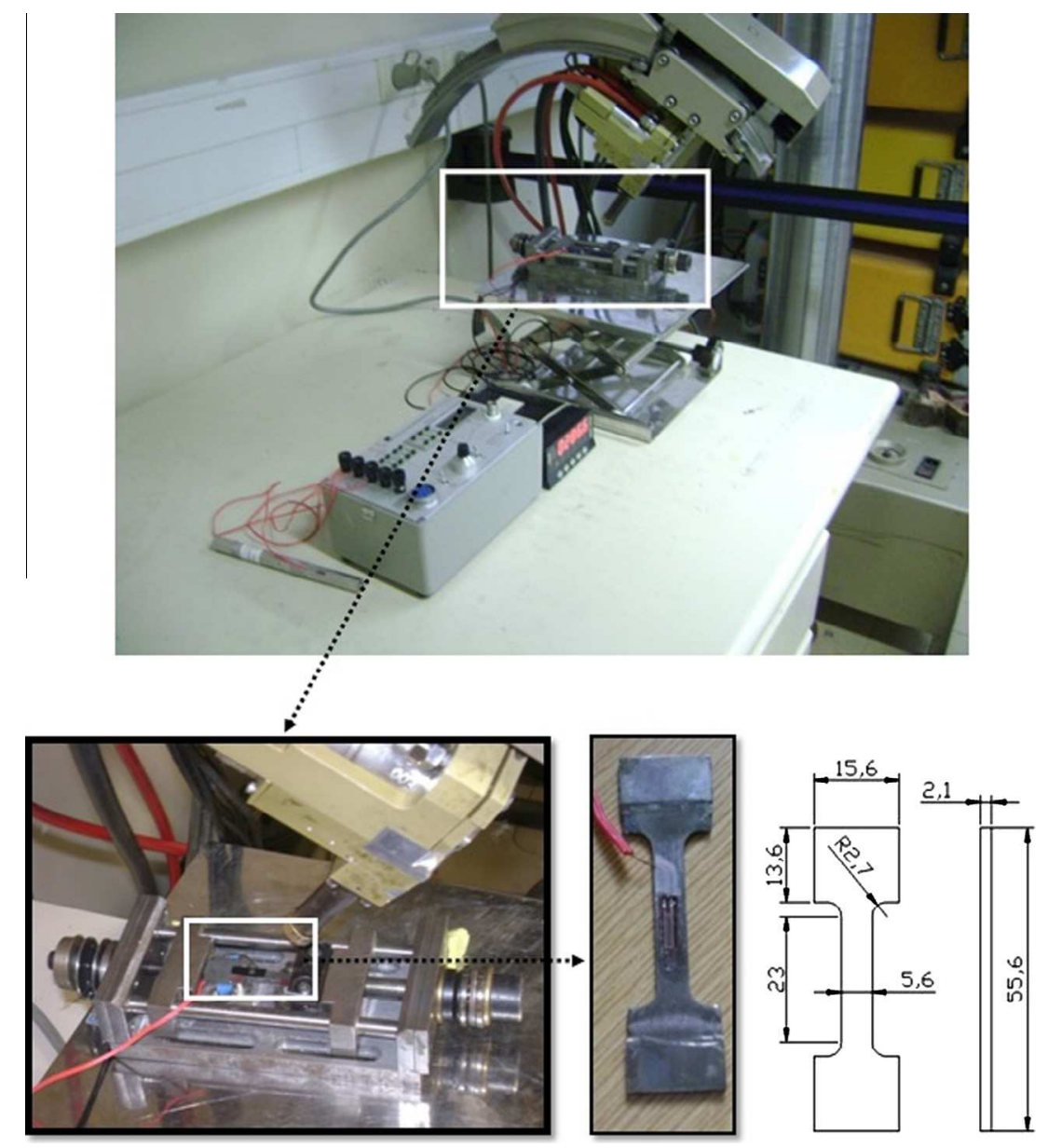

Fig. 3. Specimen shape and experimental setup used for the X-ray «in situ» tensile tests.

Table 3

X-ray diffraction parameters.

\begin{tabular}{llllll}
\hline Radiation & $\mathrm{Cr} \mathrm{K \alpha}$ & & & \\
& $\lambda=0.22911 \mathrm{~nm}$ & & & \\
Voltage & $20 \mathrm{kV}$ & & & \\
$\begin{array}{l}\text { Current } \\
\text { X-ray } \\
\text { diffraction } \\
\text { planes }\end{array}$ & $5 \mathrm{~mA}$ & $211\}=152^{\circ}$ & & & \\
$\phi$ angles & $0^{\circ}$ & & & & \\
$\psi$ angles & $39.23^{\circ}$ & $35.84^{\circ}$ & $32.31^{\circ}$ & $28.56^{\circ}$ & $24.46^{\circ}$ \\
& $19.76^{\circ}$ & $13.83^{\circ}$ & $0.0^{\circ}$ & $-9.73^{\circ}$ & $-17.02^{\circ}$ \\
& $-22.21^{\circ}$ & $-26.57^{\circ}$ & $-30.47^{\circ}$ & $-34.10^{\circ}$ & $-37.55^{\circ}$ \\
\hline
\end{tabular}

interlamellar spacing affects not only the stress state of each phase under the tensile loading but also the residual stress after unloading.

\subsection{Modeling results and validation}

\subsubsection{Self-consistent model formulation}

The self-consistent model is used in this study to identify the elastoplastic parameters (critical shear stresses $\tau_{c}^{0}$ and hardening parameters $\mathrm{H}$ ) of ferritic phase in the pearlitic steel C70.

In this work, one scale transition was adapted in which a local stress $\sigma_{i j}$ is applied on each grain. According to Schmid's law, the
Table 4

Hall-Petch parameters.

\begin{tabular}{lllllll}
\hline \multirow{2}{*}{ Steel } & $\mathrm{Re}$ & & & $\mathrm{Rm}$ & \multirow{2}{*}{ Ref } \\
\cline { 2 - 3 } \cline { 5 - 6 } & $\sigma_{0}(\mathrm{MPa})$ & $k(\mathrm{~N} / \mathrm{mm})$ & & $\sigma_{m}(\mathrm{MPa})$ & $k(\mathrm{~N} / \mathrm{mm})$ & \\
\hline C70 & 104 & 0.068 & & 506 & 0.08 & Present work \\
AISI 1080 & 205 & 0.06 & - & - & {$[18]$} \\
$0.81 \% \mathrm{C}$ & 142 & 0.05 & - & - & {$[17]$} \\
\hline
\end{tabular}

Table 5

The effect of microstructure on the parameters of Ludwik equation.

\begin{tabular}{llll}
\hline Steel & $k^{\prime}(\mathrm{MPa})$ & $n$ & Ref \\
\hline C70 (HT1) & 3398 & 0.8 & Present work \\
C70 (HT2) & 3769 & 0.8 & Present work \\
$0.8 \%$ C & 3011 & 0.65 & {$[18]$} \\
\hline
\end{tabular}

slip system $[u v w](h k l)$ (the slip direction and plane are specified) is active when the resolved shear stress $\tau[u v w](h k l)$ reaches the critical value $\tau_{\mathrm{c}}$ :

$\sigma[u v w](h k l)=\tau_{c}$

where $\tau_{c}$ is the critical shear stress, $\sigma[u v w](h k l)=(1 / 2)\left(m_{i} n_{j}+n_{i} m_{j}\right)$ $\sigma_{i j}$ is the resolved shear stress, $n=\left[n_{1}, n_{2}, n_{3}\right]$ is the unit vector normal to the $(h k l)$ plane and $m=\left[m_{1}, m_{2}, m_{3}\right]$ is the unit vector parallel to the $[u v w]$ direction. 


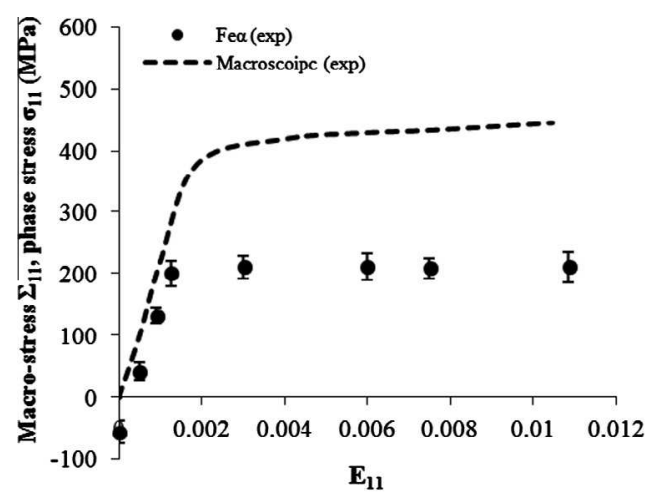

(a)

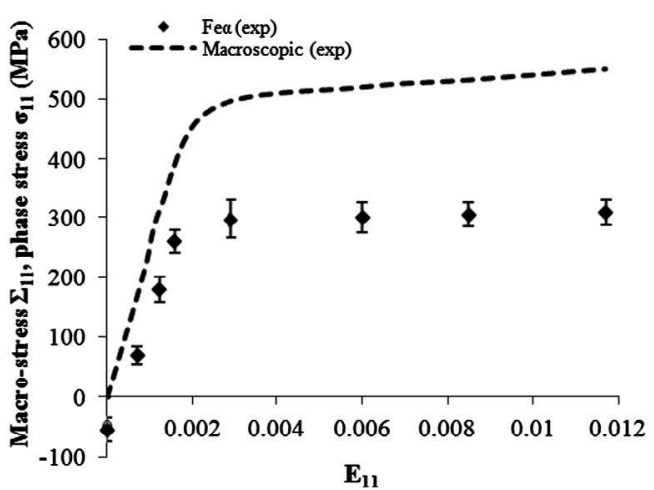

(b)

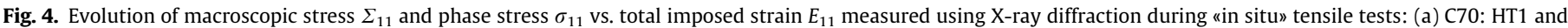
(b) C70: HT2.

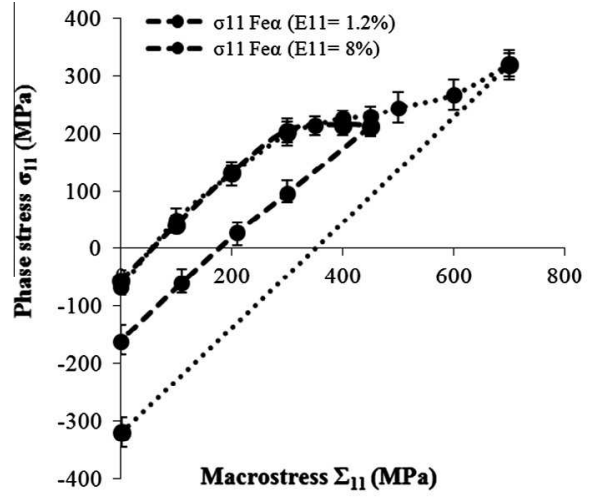

(a)

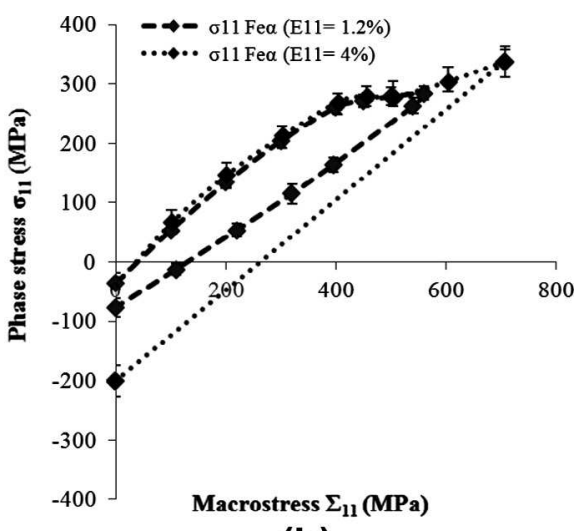

(b)

Fig. 5. Stress evolution in ferrite during loading-unloading paths for two annealed microstructures: (a) C70: HT1, (b) C70: HT2.

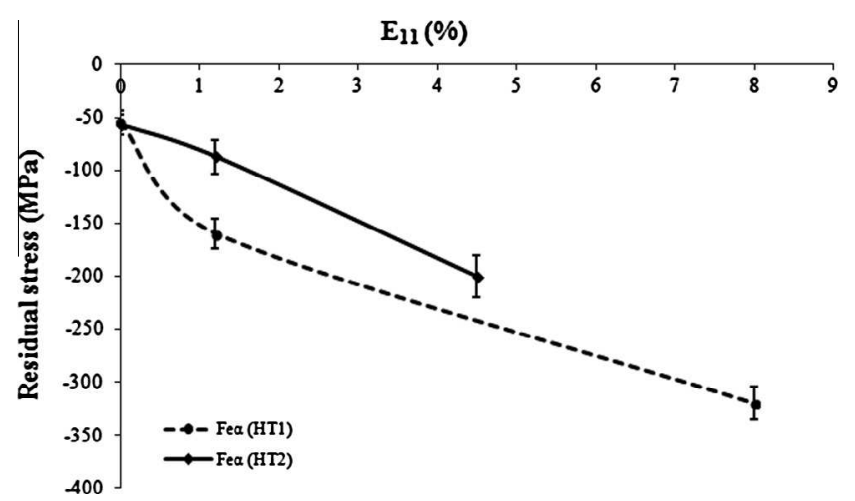

Fig. 6. Evolution of residual stress, induced by plasticity, in ferrite as a function of the total imposed strain $E_{11}$ for the two annealed microstructures.

During plastic deformation, the dislocation multiplication and their spatial configuration evolution inside a grain lead to the hardening of slip systems ( $\tau_{c}$ increases with deformation), which can be approximately described by the work hardening matrix $H^{\text {ts }}$ (i.e., the matrix reflecting the interaction between the slip systems). Consequently, the rate of the critical shear stress on the active system $\dot{\tau}_{c}^{t}$ is equal to:

$\dot{\tau}_{c}^{t}=\sum_{s} \mathrm{H}^{t s} \dot{\gamma}^{s}$

where $\dot{\gamma}^{s}$ is the rate of the plastic slip in the active system.
In the current work, the self-consistent scheme $[28,29]$ used for the scale transition and isotropic hardening was assumed, i.e., all elements of the $H^{t s}$ matrix (Eq. (5)) are equal to the same value $\mathrm{H}$. The initial critical shear stress $\tau_{c}^{0}$ and the work hardening parameter $(\mathrm{H})$ were determined using the method proposed in work of Baczmanski and Braham [30].

\subsubsection{Model parameters}

To predict the elastoplastic behavior of the two pearlitic microstructures, the calculations were carried out for 10.000 ellipsoidal inclusions representing grains of cementite (10\%) and ferrite (90\%). The average aspect ratios $(a / b=0.9$ and $0.7, a / c=0.03$ and 0.04 for HT1 and HT2 microstructure respectively) of inclusions were determined from the micrographic sections presented in Fig. 7. The orientations of axes of cementite inclusion were randomly distributed, while spherical grains were assumed for ferrite. The components of single crystal stiffness tensor of ferrite used in calculations are reported in Table 6. Random orientations distribution of lattice in ferritic grains was assumed. In the case of cementite only theoretical (ab initio calculation) tensor of single crystal elastic constants $\left(C_{i j}\right)$ is available [31]. However, the theoretical data (averaged for polycrystalline aggregate) does not agree with experimentally determined Young's modulus (E) and Poison's ratio (v) [32,33]. Finally, using synchrotron radiation during tensile test it was shown that $\mathrm{Fe}_{3} \mathrm{C}$ crystal exhibit almost isotropic elastic properties [6]. Therefore, isotropic Young's modulus and Poison's ratio (Table 6) given in [32] were attributed to the inclusions of cementite (the crystal lattice was not defined for the $\mathrm{Fe}_{3} \mathrm{C}$ grains) 


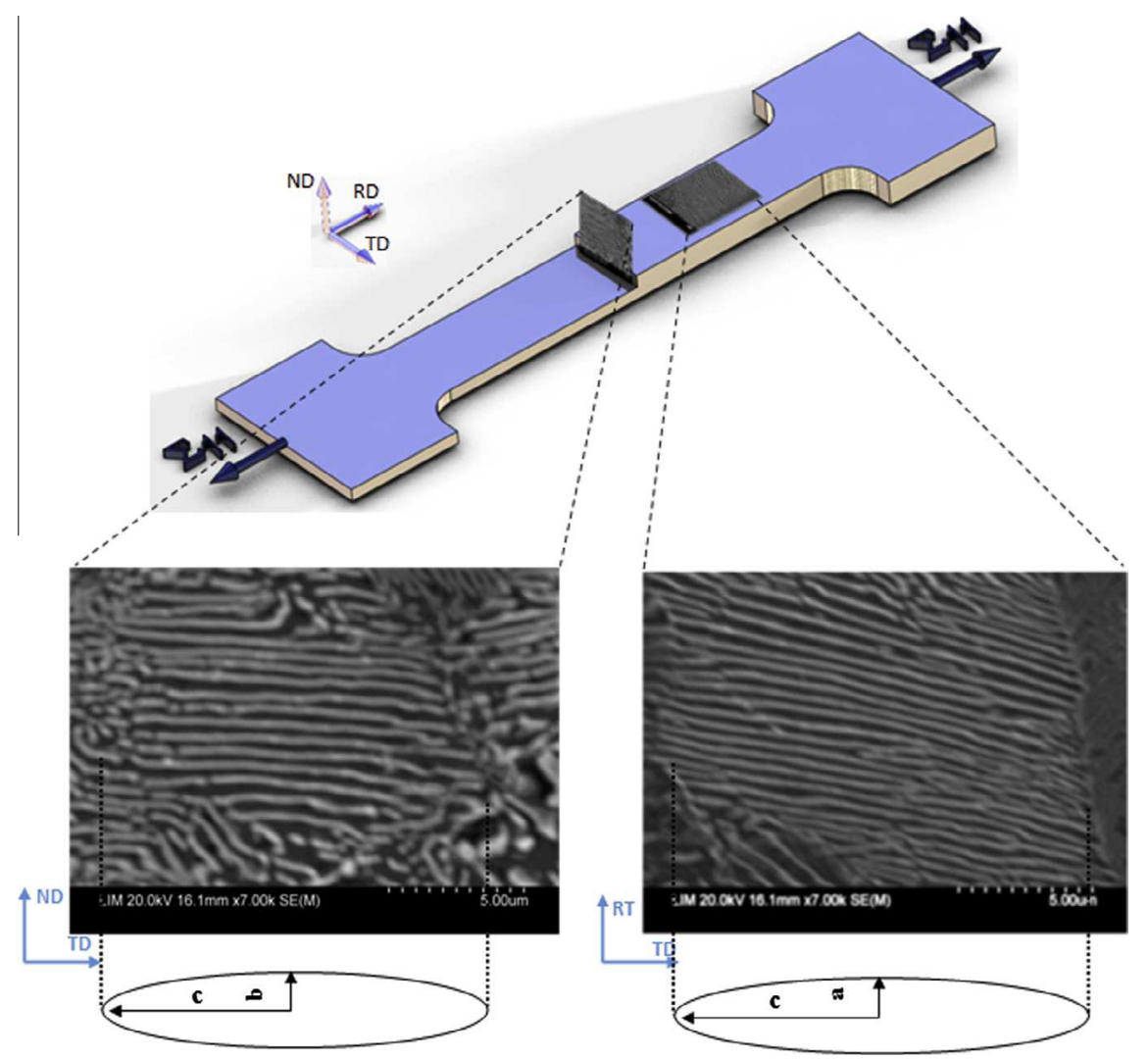

Fig. 7. The shape of the ellipsoidal inclusion used for model prediction.

Table 6

Elastic properties of phases.

\begin{tabular}{lllllll}
\hline Phase & $C_{11}(\mathrm{GPa})$ & $C_{12}(\mathrm{GPa})$ & $C_{44}(\mathrm{GPa})$ & $G(\mathrm{GPa})$ & $v$ & Reference \\
\hline Ferrite & 231.4 & 134.7 & 116.4 & - & - & {$[4]$} \\
Cementite & - & - & - & 90 & 0.275 & {$[32]$} \\
\hline
\end{tabular}

Table 7

Initial residual stresses.

\begin{tabular}{lll}
\hline Structure & Phase & $\sigma_{11}(\mathrm{MPa})$ \\
\hline C70 (HT1) & Ferrite (measured) & $-56 \pm 13$ \\
& Cementite (calculated) & 504 \\
C70 (HT2) & Ferrite (measured) & $-55 \pm 18$ \\
& Cementite (calculated) & 495 \\
\hline
\end{tabular}

Two slip systems $\langle 111\rangle\{211\}$ and $\langle 111\rangle\{110\}$ in ferritic phase were used in calculations for the HT1 and HT2 microstructures. For both microstructure samples the initial residual stresses in ferrite were measured by X-ray diffraction and those of cementite were estimated using a mixture law $[7,34]$ :

$$
(1-f) \sigma_{\mathrm{Fe \alpha}}^{R}+f \sigma_{\mathrm{Fe}_{3} \mathrm{C}}^{R}=0
$$

where $\sigma_{\mathrm{Fe \alpha}}^{R}$ is the residual stress in ferrite, $\sigma_{\mathrm{Fe}_{3} \mathrm{C}}^{R}$ is the residual stress in the cementite and $f$ is the volume fraction of the cementite. The levels of the initial residual stresses are given in Table 7. The initial residual stresses, which are assumed to be equal for all grains in the same phase, were assigned to the inclusions.

\subsubsection{Results and validation}

4.2.3.1. Plasticity parameters. An elastic behavior of cementite was assumed for the whole range of deformation as indicated by the literature data $[6,13,14,22]$. The ferrite shear stress $\tau_{c}^{0}(\alpha)$ and the hardening parameter $\mathrm{H}$, for both microstructures, were identified on the basis of the iterative choosing of plasticity parameters in calculations that ensure an optimal agreement with the "in situ» X-ray tensile data ( $\left.\sigma_{11}-E_{11} \mathrm{plot}\right)$ presented in Figs. 8a and 9a. In this case, due to shortage of experimental X-ray data for cementite, only the stresses measured in ferritic phase were compared with model prediction. The validity of the self-consistent calculations can be accessed from the comparison of macroscopic tensile test with model results, obtained with parameters for which the best agreement of X-ray data was achieved. Such comparison of the macroscopic $\Sigma_{11}-E_{11}$ plots, shown in Figs. $8 \mathrm{~b}$ and $9 \mathrm{~b}$, reveals a good agreement for the two annealed microstructures. However, a small underestimation of the theoretical macro-stresses can be observed.

We can conclude that the values of plastic parameters obtained by fitting model to the X-ray data are also underestimated (i.e. the lower bound for $\tau_{c}^{0}(\alpha)$ was found, when value of $H$ remains always close to zero). To obtain the upper limit of shear stresses the fitting of model macroscopic curve to the result of mechanical tensile test ( $\Sigma_{11}-E_{11}$ plot) was also done. Certainly in this case the stresses predicted in ferrite exceed the experimental X-ray data.

The limits of the optimal values of the parameters $\tau_{c}^{0}(\alpha)$ and $\mathrm{H}$ ensuring the good agreement between experimental and theoretical data are given in Table 8. Indeed, the value of the ferritic initial critical shear stress $\tau_{c}^{0}$ is much higher for the smaller interlamellar spacing of the pearlitic microstructure (HT2). The value of the parameter $\mathrm{H}$ identified by modeling is close to zero, which is conform with the low hardening of the ferrite phase as described by the experimental behavior of this phase (Fig. 4). Also, different values of yield stresses of ferrite (corresponding to determined $\tau_{c}^{0}(\alpha)$ ) were found for both microstructures, i.e.: $\sigma_{y 1}=210-230 \mathrm{MPa}$ for HT1 and $\sigma_{y 2}=280-308 \mathrm{MPa}$ for HT2. 


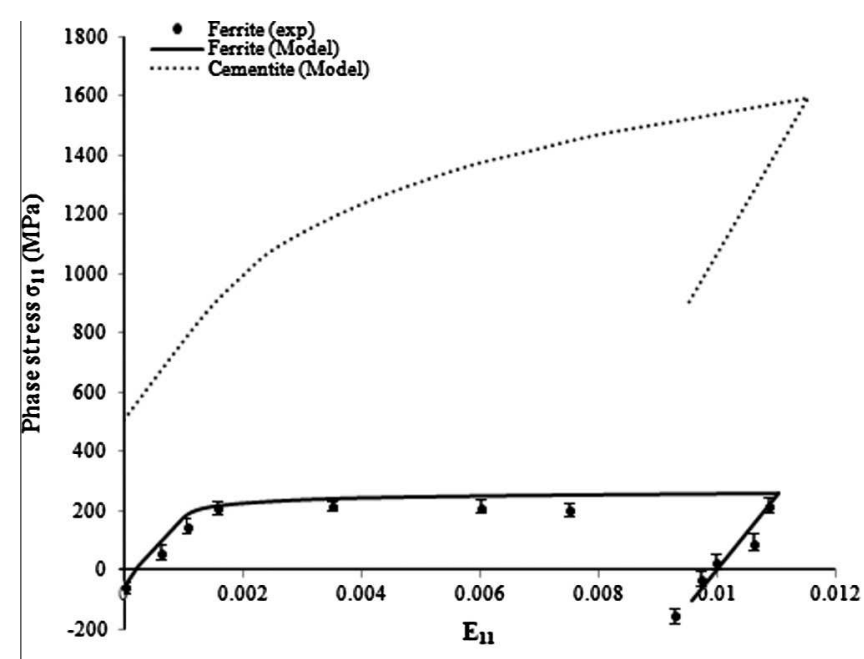

(a)

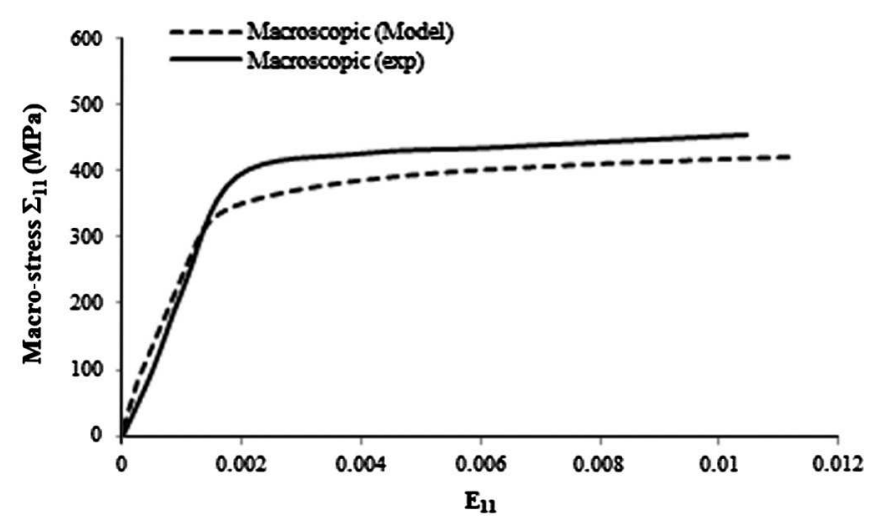

(b)

Fig. 8. The results of the "in situ» tensile test compared with the model prediction for C70 HT1 microstructure: (a) macroscopic stress $\Sigma_{11}$ vs. $E_{11}$ steel; (b) ferrite stress $\sigma_{11}$ vs. $E_{11}$. Also, the evolution of theoretical stress in cementite vs. $E_{11}$ is shown.

It is important to notice that for high macroscopic applied stress, a significant deviation between modeling and experimental behavior of ferrite has been observed (Fig. 10). The predicted stress in ferrite is lower than the value measured by X-ray for an imposed strain equal or higher than (7\%). This deviation could be explained by the partial stress relaxation attributed to the cementite fracture occurring at the high applied stress level ( $\Sigma_{11}=700 \mathrm{MPa}$ ) (Fig. 11). Therefore, an increase of locally measured stress indicates that applied load is mainly transferred into the ferrite phase. The damage effect is not considered in the self-consistent model.

4.2.3.2. Residual stress induced by plasticity. The model can recover the experimental value of the compressive residual stresses in ferrite after loading (applied stress ratio $\frac{\Sigma_{11}}{R_{e}}$ equal to 1.1 ) followed by unloading for both annealed pearlitic microstructures (Figs. 8(a) and 9(a)). Their levels increase with increasing the interlamellar spacing. Moreover, the self-consistent model can be used to predict the level of residual stress induced by plasticity in cementite phase. As expected, the residual stress in cementite phase is a tensile one.

\section{Discussion}

In this investigation, the influence of microstructure characteristics on the macroscopic and microscopic behavior of $C 70$ pearlitic

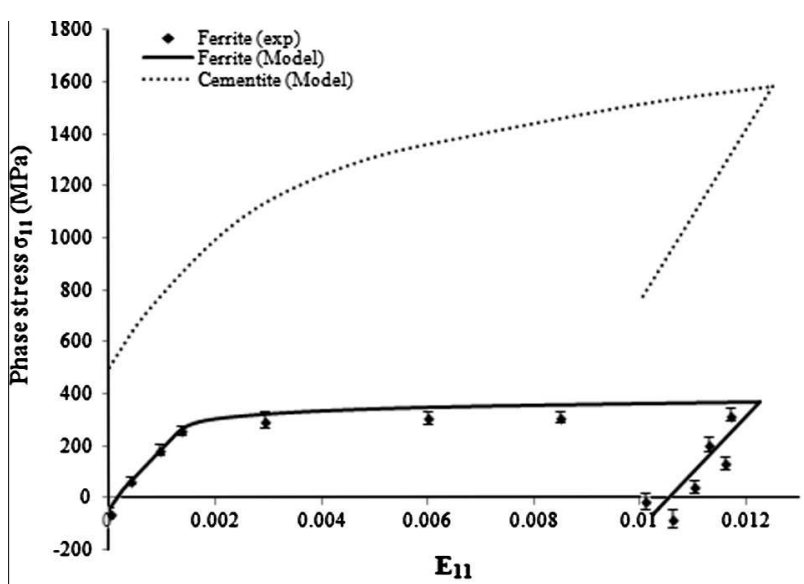

(a)

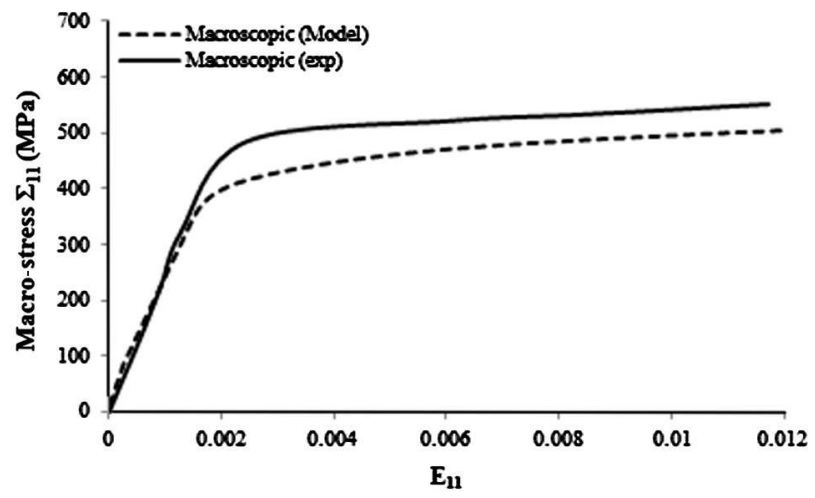

(b)

Fig. 9. The results of the "in situ» tensile test compared with the model prediction for C70 HT2 microstructure: (a) macroscopic stress $\Sigma_{11}$ vs. $E_{11}$ steel; (b) ferrite stress $\sigma_{11}$ vs. $E_{11}$. Also, the evolution of theoretical stress in cementite vs. $E_{11}$ is shown.

Table 8

Ferrite parameters of plasticity identified by self-consistent model.

\begin{tabular}{llcl}
\hline Phase & Structure & $\tau_{c}^{0}(\mathrm{MPa})$ & $\mathrm{H}(\mathrm{MPa})$ \\
\hline \multirow{2}{*}{ Ferrite } & C70:HT1 & $75-86$ & 2 \\
\multirow{2}{*}{ Cementite } & C70:HT2 & $105-120$ & 2 \\
\hline
\end{tabular}

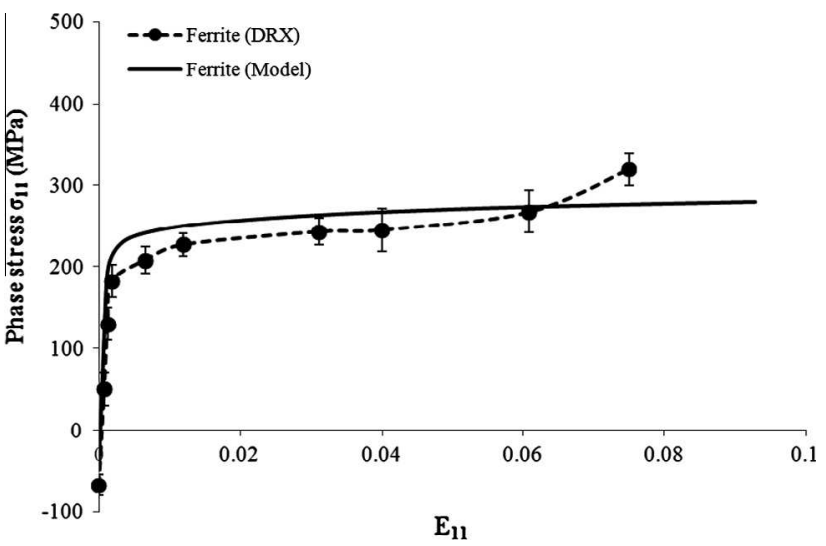

Fig. 10. The result of «in situ» tensile test is compared with the model prediction for ferrite in C70: HT1 microstructure (relatively large deformation range, until damage). 


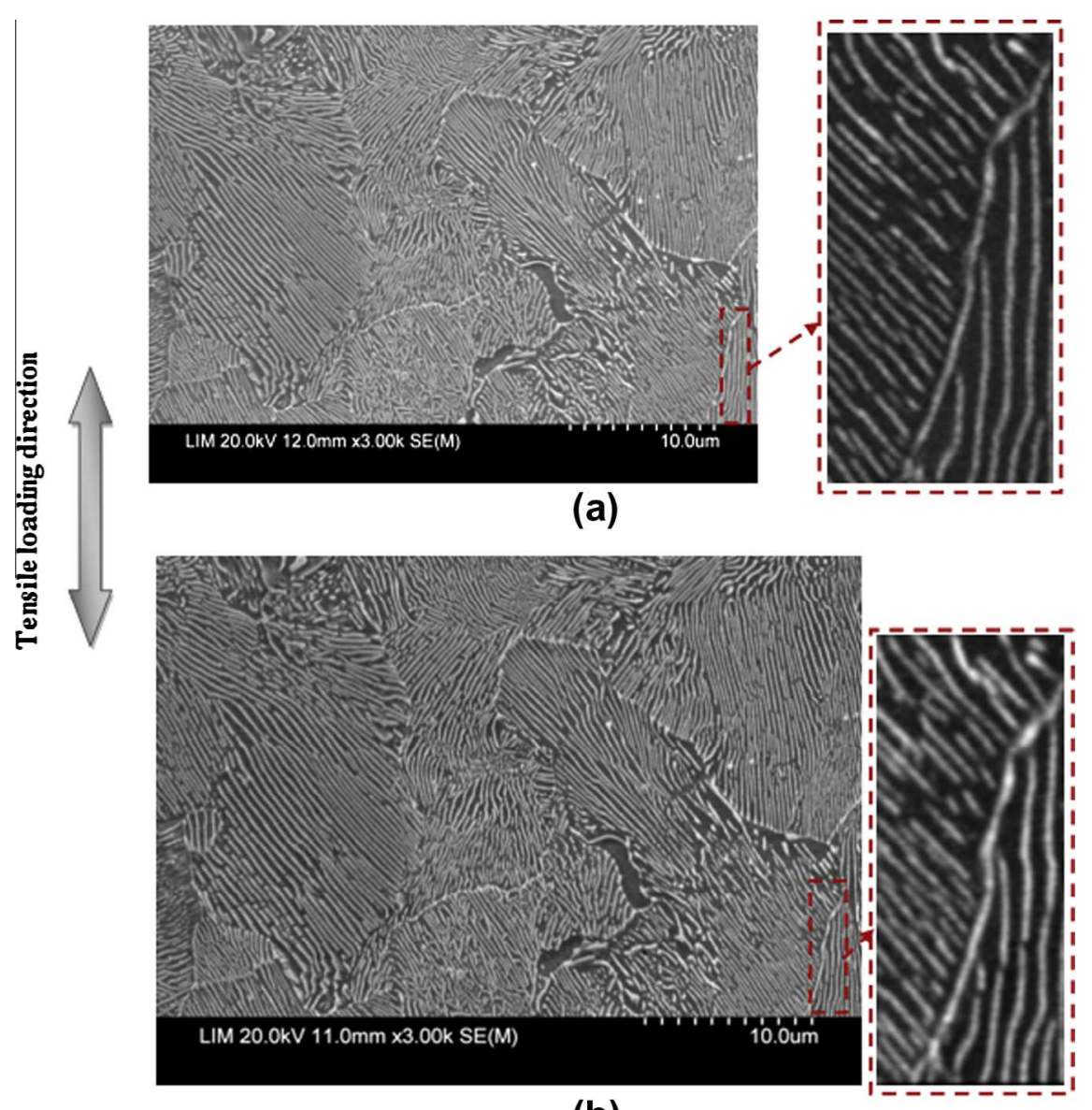

(b)

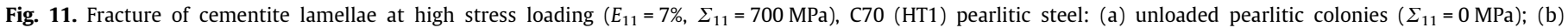
$\left(\Sigma_{11}=700 \mathrm{MPa}\right)$.

steel was established. It was found that, for a given cementite volume fraction, the strength of pearlitic steel as well as of ferritic phase is mainly controlled by the interlamellar spacing.

\subsection{Effect of interlamellar spacing on pearlitic steel behavior}

C70 steel tensile results, obtained in this study, show an increase in the yield stress and the ultimate tensile strength for smaller interlamellar spacing. These results are consistent with previous investigations on eutectoid [16], hyper-eutectoid [21,27] and hypo-eutectoid $[2,19,21]$ steels.

It has been showed in this study that yield stress and ultimate tensile strength of pearlitic steel are controlled by the interlamellar spacing as expressed by a modified Hall-Petch relation (Eq. (2)). The linearity of relation is validated for a wider range of interlamellar spacing integrating results of C70 pearlitic steel and literature data $[17,18]$ as confirmed by the diagram $\ln \left(\sigma_{y}-\sigma_{0}\right)=\mathrm{f}(\ln (\mathrm{Sp}))$ (Fig. 12). In this diagram experimental values of yield stress vary linearly in accordance with a slope of $(-1)$ with interlamellar spacing $\mathrm{Sp}$.

The yield strength of pearlite is consistent with the stress necessary to move dislocations in ferrite between two impenetrable cementite lamellae, which increases with interlamellar spacing refinement leading to strengthening. This explanation is based on the assumption that dislocation sources are activated in cementite-ferrite interfaces and their displacement is controlled by a mean free path $\langle\mathrm{L}\rangle$ quite equal to the interlamellar spacing $\mathrm{Sp}$. As a result, when the interlamellar spacing is large, dislocations move more freely in the ferrite zone, resulting in lower yielding limit $\left(\sigma_{y}\right)$

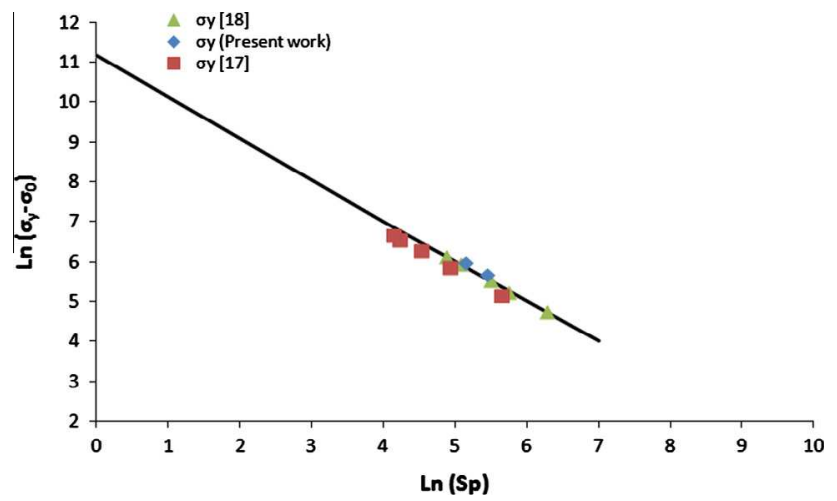

Fig. 12. Evolution of yield strength $\sigma_{y}$ vs. interlamellar spacing Sp.

and ultimate tensile strength (UTS). This result is consistent with previous work performed on the eutectoid steels $[2,16,18,27]$.

Ludwik strengthening parameter $(n=0.8)$ for two microstructures indicate that the work hardening of pearlite does not depend on the interlamellar spacing. This value is quite similar to that of Dollar et al. [18] as shown in Table 5.

\subsection{Effect of interlamellar spacing on ferrite behavior}

The results of «in situ» X-ray tensile test show a high yield stress of ferritic phase for the small interlamellar spacing. This result is 


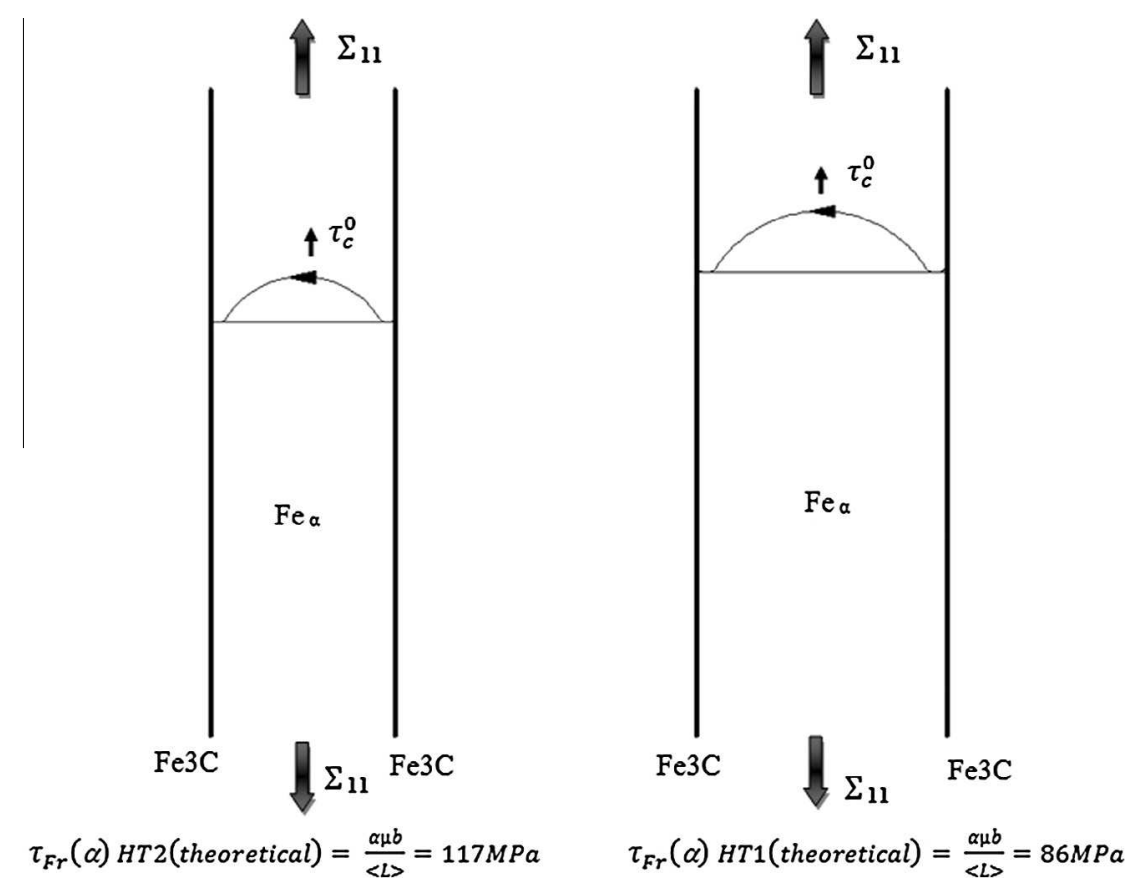

Fig. 13. Scheme showing the effect of interlamellar spacing on the theoretical ferrite critical shear stress $\tau_{F r}(\alpha)$.

Table 9

Critical resolved shear stress for ferrite.

\begin{tabular}{lll}
\hline Microstructure & $\begin{array}{l}\tau_{c}^{0}(\alpha)(\mathrm{MPa}) \text { (self consistent } \\
\text { model) }\end{array}$ & $\begin{array}{l}\tau_{\mathrm{Fr}}(\alpha)(\mathrm{MPa}) \text { (Frank-Read } \\
\text { equation) }\end{array}$ \\
\hline C70 (HT1) & 75 & 86 \\
C70 (HT2) & 105 & 117 \\
\hline
\end{tabular}

consistent with the ferrite critical shear stress $\left(\tau_{c}^{0}(\alpha)\right)$ identified by the self-consistent model for the two studied annealed microstructures. Indeed, the critical shear stress $\left(\tau_{c}^{0}(\alpha)\right)$ gets higher when the interlamellar spacing decreases. It can be explained by the mean free path of mobile dislocations $\langle\mathrm{L}\rangle$ controlling the critical shear stress according to substructure deformation analyzed by $\mathrm{Li}$ et al. [35]. The critical shear stress represents the stress necessary to activate the Frank-Read mechanism of a ferrite-cementite interface generated dislocation (Fig. 13). The interlamellar spacing Sp represents the line of initial dislocation pinned between two cementite lamellae. As the force resulting from the applied stress increases, the dislocation bows to the point where it equals $\mathrm{Sp} / 2$ and a new dislocation is generated within the confine of a single pearlite lamellae. The dislocation enfranchisement is ensured when the resolved shear stress is equal to $\tau_{\mathrm{Fr}}$ as expressed by Eq. (7).
$\tau_{F r}=\tau_{c}^{0}=\frac{\alpha \mu b}{\langle L\rangle}$

In this equation: $b$ is the Burgers vector $=a / 2\langle 111\rangle=$ $2.5 \times 10^{-10} \mathrm{~m}$ for ferritic steel, $\alpha$ equals to $1, \mu$ is the shear modulus $=80,000 \mathrm{MPa}$ for the steel and $\langle\mathrm{L}\rangle \approx \mathrm{Sp}$ is the mean free path for mobile dislocations.

The calculated shear stresses for the two annealed microstructures, according to Eq. (7), are compared to those identified by the self-consistent model in Table 9. It confirms the role of cementite lamellae as an obstacle for dislocation movement that controls the deformation of ferrite phase. Using Eq. (7), the effect of interlamellar spacing on the ferrite strength has been shown by comparing the interlamellar spacing ratio $\frac{S_{p}(H T 1)}{S_{p}(H T 2)} \approx 1.4$ to the critical shear stress ratio $\frac{\tau_{c}^{0}(\alpha)(H T 2)}{\tau_{c}^{0}(\alpha)(H T 1)} \approx 1.4$ identified by the self-consistent model. In the same manner, the role of ferritic flow stress that depends on the critical shear stress, on the C70 steel yield stress has been determined by comparing the ratio $\frac{\sigma_{y} \alpha(H T 2)}{\sigma_{y} \alpha(H T 1)} \approx 1.3$ to $\frac{\sigma_{y} C 70(H T 2)}{\sigma_{y} C 70(H T 1)} \approx 1.3$. This result is consistent with that of Dollar et al. [18] where it was indicated that yielding of pearlitic steel is mainly controlled by the deformation processes occurring in ferrite.

Table 10

Residual stress partitioning in pearlite phases $\left(E_{11}=1.2 \%\right)$.

\begin{tabular}{|c|c|c|c|c|c|c|c|c|c|}
\hline \multirow[t]{3}{*}{ Steel } & & \multicolumn{7}{|c|}{ Residual stress (MPa) } & \multirow[t]{3}{*}{ Reference } \\
\hline & & \multicolumn{4}{|c|}{ Experimental results } & \multicolumn{3}{|c|}{ Modeling results } & \\
\hline & & Ferrite & Cementite & $\left|\frac{\sigma_{\text {Fe3C }}^{R}}{\sigma_{\text {Fex }}^{R}}\right|$ & Method & Ferrite & Cementite & $\left|\frac{\sigma_{F e 3 C}^{R}}{\sigma_{F e \alpha}^{R}}\right|$ & \\
\hline \multirow[t]{2}{*}{$\mathrm{C} 70$} & HT1 & -150 & - & - & X-ray & -120 & 900 & 7.5 & Present work \\
\hline & HT2 & -77 & - & - & & -70 & 760 & 10 & \\
\hline \multicolumn{2}{|c|}{ Pearlitic steel } & -150 & 720 & 5 & X-ray Synchrotron & - & - & - & {$[4]$} \\
\hline \multicolumn{2}{|c|}{$0.78 \% \mathrm{C}$} & - & - & - & X-ray Synchrotron & -200 & 1000 & 5 & [5] \\
\hline \multicolumn{2}{|c|}{$0.48 \% \mathrm{C}$} & - & - & - & - & -90 & 600 & 6 & {$[22]$} \\
\hline
\end{tabular}




\subsection{Effect of interlamellar spacing on residual stress induced by plasticity}

X-ray diffraction measurements as well as self-consistent model show compressive residual stress in ferrite and the self-consistent model estimates the tensile residual stress in cementite for the loading-unloading path of the test performed in this study. The obtained experimental and model results are in the same order of magnitude as those available in the literature for various carbon steels and different assessment methods as it is shown in Table 10. It-is important to notice that the residual stress partitioning ratio $\left|\frac{\sigma_{\text {Fe3C }}^{R}}{\sigma_{\text {Fex }}^{R}}\right|$ is equal to 7.5 and 10 for C70 HT1 and HT2 microstructures respectively. Such difference in residual stress distribution between ferrite and cementite is consistent with that reported in the literature as shown in Table 10. This difference is attributed to a high contrast in the mechanical behavior between ferrite and cementite phases [4]. Moreover, the residual stress distribution is influenced by interlamellar spacing. It was found that the lower residual stress levels are associated with smaller interlamellar spacing for the same loading-unloading path. Indeed, the plastic deformation is always associated with the free dislocations movement in the softer ferritic phase while the cementite still deforms elastically until it breaks. Consequently, when the interlamellar spacing is larger, the dislocations move more freely in the ferritic phase and contribute to the high local cumulated deformation. Then, the created plastic incompatibility between the two phases is more important resulting in a higher residual stress level. That is why the compressive residual stress increases with increasing the interlamellar spacing.

\section{Conclusions}

In this study, the effect of interlamellar spacing on the behavior of C70 pearlitic steel was investigated by X-ray "in situ" tensile tests coupled with self-consistent model. The main results can be summarized as follow:

- Yielding of pearlite depends mainly on interlamellar spacing and follows the modified Hall-petch relationship: $\sigma_{j}=\sigma_{0}+k_{j} S_{p}^{-1}$. However, Ludwik work hardening coefficients $(n=0.8)$ is not influenced by interlamellar spacing.

- Yielding of ferrite, studied by "in situ» $\mathrm{X}$-ray tensile test results is controlled by the interlamellar spacing: $\sigma_{y(\mathrm{Fe} \alpha)}=280 \mathrm{MPa}$ for $\mathrm{Sp}=170 \mathrm{~nm}$ and $\sigma_{y(\mathrm{Fe} \alpha)}=210 \mathrm{MPa}$ for $\mathrm{Sp}=230 \mathrm{~nm}$. This result is consistent with the ferrite critical shear stress identified by the self-consistent model: $\tau_{c}^{0}(\alpha)=105-120 \mathrm{MPa}$ and $\tau_{c}^{0}(\alpha)=75-$ $86 \mathrm{MPa}$ for $\mathrm{Sp}=170 \mathrm{~nm}$ and $\mathrm{Sp}=230 \mathrm{~nm}$, respectively.

- Plastic deformation of pearlitic steel induces compressive residual stresses in ferrite and tensile ones in cementite with respect to the ratio $\left|\frac{\sigma_{\text {Fe3C }}^{R}}{\sigma_{\text {Fex }}^{R}}\right|$ that equals to 7.5 and 10 for C70 HT1 and C70 HT2 microstructures respectively. Residual stress levels of the two phases are higher for the largest interlamellar spacing.

\section{References}

[1] Langford G. Deformation of Pearlite. Metall Trans A 1977;8A:861-75.

[2] Modia OP, Deshmukh N, Mondala DP, Jhaa AK, Yegneswarana AH, Khairac HK Effect of interlamellar spacing on the mechanical properties of $0.65 \% \mathrm{C}$ steel. Mater Charact 2001;46:347-52.

[3] Perez-Unzueta AJ, Beynon JH. Microstructure and wear resistance of pearlitic rail steels. Wear 1993:162-164A:173-82.

[4] Inal K, Lebrun JL, Belassel M. Second-order stresses and strains in heterogeneous steels: self-consistent modeling and X-ray diffraction analysis. Metall Mater Trans 2004;35A:2361-9.
[5] Belassel M. Etude de la distribution de contraintes d'ordre I et II par diffraction $\mathrm{X}$ dans un acier perlitique [Thesis]: ENSAM Paris; 1994

[6] Young ML, Almer JD, Daymond MR, Haeffner DR, Dunand DC. Load partitioning between ferrite and cementite during elasto-plastic deformation of an ultrahigh-carbon steel. Acta Mater 2007;55:1999-2011.

[7] Taupin V, Pesci R, Berbenni S, Berveiller S, Ouahab R, Bouaziz O. Lattice strainmeasurementsusing synchrotrondiffraction to calibrate a micromechanical modeling in a ferrite-cementite steel. Mater Sci Eng 2013;A561:67-77.

[8] Tomota Y, Lukas P, Neov D, Harjo S, Abe YR. «In situ » neutron diffraction during tensile deformation of a ferrite-cementite steel. Acta Mater 2003;51:805-17.

9] Daymond MR, Priesmeyer HG. Elastoplastic deformation of ferritic steel and cementite studied by neutron diffraction and self-consistent modelling. Acta Mater 2002;50:1613-26.

[10] Tomota Y, Suzuki T, Kanie A, Shiota Y, Uno M, Moriai A, et al. In situ neutron diffraction of heavily drawn steel wires with ultra-high strength under tensile loading. Acta Mater 2005;53:463-7.

[11] Kanie A, Tomota Y, Torii S, Kamiyama T. Elastic strains of cementite in a pearlite steel during tensile deformation measured by neutron diffraction. ISIJ Int 2004:44:1952-6.

[12] Lei C, Masahide G, Yoshiaki H, Yukio H. Effect of microstructure of cementite on interphase stress state in carbon steel. J Iron Steel Res Inter 2007:14(4):31-8.

[13] Lei C, Gotoh M, Horimoto Y, Hirose Y, Yang L. Characterization of deformability of spheroidal cementite by residual stress measurement. J Mater Eng Perform 2008:17:445-53.

[14] Oliver EC, Daymond MR, Withers PJ. Interphase and intergranular stress generation in carbon steels. Acta Mater 2004;52:1937-51.

[15] Shinozaki T, Morooka S, Suzuki T, Tomota Y, Kamiyama T. Influence of lamellar spacing on deformation behavior of pearlite steels studied by "in situ " neutron diffraction. In: The 3rd international conference on advanced structural steels gyeongju. Korea 2006.

[16] Hyzak JM, Bernstein IM. The role of microstructure on the strength and toughness of fully pearlitic steels. Metall Trans A 1976;7A:1218-24.

[17] Marder AR, Bramfitt BL. The effect of morphology on the strength of pearlite. Metall Trans A 1976;7A:365-72.

[18] Dollar M, Bernstein M, Thompson AW. Influence of deformation substructure on flow and fracture of fully pearlitic steel. Acta Metall 1988;36:311-20.

[19] Kazeminezhad M, Karimi Taheri A. The effect of controlled cooling after hot rolling on the mechanical properties of a commercial high carbon steel wire rod. Mater Des 2003:24:415-21.

[20] Porter DA, Easterling KE, Smith GDW. Dynamic studies of the tensile deformation and fracture of pearlite. Acta Metall 1978;26:1405-14.

[21] Wu M, Hua L, Shao YC, Zhou OJ. Influence of the annealing cooling rate on the microstructure evolution and deformation behaviours in the cold ring rolling of medium steel. Mater Des 2011;32:2292-300.

[22] Schmitt C Lipinski P, Berveiller M. Micromechanical modelling of the elastoplastic behavior of polycrystals containing precipitates-application to hypo- and hyper-eutectoid steels. I J Plast 1997;13(3):183-99.

[23] Long X, Peng X, Pi W. A microstructure-based analysis of cyclic plasticity of pearlitic steels with Hill's self-consistent scheme incorporating general anisotropic Eshelby tensor. Acta Mech Sin 2008;24:91-9.

[24] Abrams H. Grain size measurement by the intercept method. Metallography $1971 ; 4: 59-78$

[25] Hu X, Houtte PV, Liebeherr M, Walentek A, Seefeldt M, Vandekinderen H. Modeling work hardening of pearlitic steels by phenomenological and Taylortype micromechanical models. Acta Mater 2006;54:1029-40.

[26] NF EN 15305, Essais non-destructifs: méthode d'essai pour l'analyse des contraintes résiduelles par diffraction des rayons X, AFNOR, 2009.

[27] Elwazri AM, Wanjara P, Yuea S. The effect of microstructural characteristics of pearlite on the mechanical properties of hypereutectoid steel. Mater Sci Eng A 2005;404:91-8.

[28] Baczmański A, Zattarin P, Lipiński P, Wierzbanowski K. Modified selfconsistent model for time independent plasticity of polycrystalline material. Arch Metall 2000:45:163-84.

[29] Lipinski P, Berveiller M. Elastoplasticity of micro-inhomogeneous metals at large strains. I J Plast 1989;5:149-52.

[30] Baczmanski A, Braham C. Elastoplastic properties of duplex steel determined using neutron diffraction and self-consistent model. Acta Mater 2004;52:1133-42.

[31] Jiang C., Srinivasan SG, Caro A, Maloy SA. Structural, elastic and electronic properties of Fe3C from first-principles. J Appl Phys. 2008;103.

[32] Ledbetter H. Polycrystalline elastic constants of in situ cementite (Fe3C). Mater Sci Eng 2010; A 527:2657-61.

[33] Mizubayashi H, Li SJ, Yumoto H, Shimotomai M. Young's modulus of single phase cementite. Script Mater 1999;40(7):773-7.

[34] Pescia R, Inal b K, Massonc R. Three scale modeling of the behavior of a 16MND5-A508 bainitic steel: stress distribution at low temperatures. Mater Sci Eng A 2009;527:376-86.

[35] Li S, Yip TH, Ramanujan RV, Liang MH. In situ TEM studies of the mechanisms of crack nucleation and propagation in fully lamellar microstructures. Mater Sci Technol 2003;19:902-6. 